\title{
HARLOW SHAPLEY AND THE UNIVERSITY OF MISSOURI
}

\author{
Charles J. Peterson \\ University of Missouri - Columbia
}

The Laws Observatory of the University of Missouri is an example of the small university observatory that under lean financial circumstances succeeded for a number of years (1890-1920) as a successful research institution. Productive research appears to have been due to the temperament of the individual astronomers who had the ability to find projects which could be accomplished with small telescopes, minimal equipment, and few other resources. In these circumstances, a handful of students began careers in astronomy at the University of Missouri.

The Laws Observatory began in 1880 with the acquisition of a 7.5 inch Merz und Sohne refractor originally manufactured in 1848. Initially used only for instructional purposes, this changed with establishment of a Department of Astronomy in 1893 under the direction of Milton Updegraff, the first professionally trained astronomer on the faculty. Both the size and age of the Merz telescope were handicaps to Ipdegraff; however, many observatories with newer and larger telescopes were much less productive in research. Lack of funds for repairs and to modernize the Observatory equipment were not all that troubled him; appended to an "Observatory Report" (Jpdegraff 1894, Observatory 17, 246), the editors noted, "We hope to hear more of Mr. Updegraff, although he is somewhat hampered with his University duties." Jpdegraff resigned in 1899 and was soon replaced by Frederick H. Seares.

Although many of the problems about which Updegraff had so persistantly complained continued through the tenure of Seares, Seares seems to have been more able to work under the conditions that prevailed. His requests for renovation of observatory facilities tended to be less expensive and with improvement in University finances [these years would actually be long remembered as a Golden Age according to later University historians (F.F. Stephens 1962, A History of the University of Missouri)], limited resources became available for new equipment and other needs. As Seares would later write (19 0ctober 1911) to his successor: "I hope that you may have as much pleasure in the work there as I had during the years that I held the position. As you say, the observatory is not what one would call modern." In reference to the main telescope, "I am afraid the driving clock of the 7 1/2 inch is hopeless. I never attempted to use it for any purpose except to keep the instru- 
ment under way in a rough kind of fashion when visitors were using the instrument." Otherwise, "you will find any amount of polite interest in the affairs of the institution, but it is extremely difficult to carry the matter beyond that point, - at least such was my experience. The University authorities themselves, however, I always found to be most generously inclined within the limits of their financial abilities, which, of course, were necessarily very limited...." Thus in an era in which research at the University was not considered a highly important part of the duties of a professor, Seares was able to bulld a reputation for research.

Actually Seares was able to make considerable additions to the $0 \mathrm{~h}-$ servatory equipment. Of particular relevance to his observations of variable stars we re acquisitions of Pickering photometer (which used a calibrated absorbing wedge to dim an artificial light source to match the brightness of the star being observed) and a 7öllner-Müller photometer (which used polarizing prisms to vary the intensity of the artificial comparison light). These instruments were mounted on a new 4.5 inch refractor permitting work on fifth to tenth magnitude stars. He also acquired by gift a significant addition of books and journals for the observatory library and initiated the Laws Observatory Bulletin.

In this environment, the young Harlow Shapley was introduced to astronomy. The astronomy program was small and shapley was the only astronomy major at the time. In 1908 Seares requested and received funds ( $\$ 300$ per annum) for a student assistant a) to work as a stenographer to care for the "burdensome" Observatory correspondence, b) to assist in the reduction of observations, and c) to take care of miscellaneous duties such as winding clocks. Thus after only two years as a student, Shapley essentially became a staff member sharing responsibilities with Professor Seares and Instructor Eli S. Haynes who had also studied under Seares. This was in part due to the flexible structure of required credits. Although a number of astronomy courses were listed in the University Catalogue, there were really only two, an introductory course which Shapley ended up teaching (as part of his miscellaneous duties?) and a course in practical astronomy using a text that Seares had written. The other courses were given more in the manner of private discussion with Seares. As for research, Shapley joined in the observation of variable stars, noting years later that "we got some of our education hy finding faults in the instruments." Nevertheless, Shapley could still say that the Laws Observatory was a complete observatory. With the two small telescopes, Shapley, Seares, and Haynes accomplished a fair amount of observational work, primarily on eclipsing variable stars, which well prepared Shapley for his subsequent doctoral research at Princeton under the supervision of Henry Norris Russe11. By then, however, Seares had left for better opportunities at Mt. Wilson Observatory and Haynes had gone to Lick Observatory for additional study. Robert H. Baker assumed the Professorship of Astronomy at the University of Missouri in 1911, but after nearly a decade of frustration and inability to obtain a more modern observational facility, he resigned to take a position at the University of Illinois. With his departure, the Laws Observatory ceased to be a research institution. 